\title{
Antibiotic Resistance Pattern in Pediatric Deep Neck Space Infection
}

\author{
Bijaya Kharel $^{1(0)}$ Kapil Shahi $^{10}$ Urmila Gurung $^{1(0)}$ \\ ${ }^{1}$ Department of ENT - Head and Neck Surgery, Tribhuvan University \\ Teaching Hospital, Institute of Medicine, Kathmandu, Nepal \\ Address for correspondence Bijaya Kharel, MS, ENT-HNS, \\ Department of ENT- Head and Neck Surgery, Tribhuvan University \\ Teaching Hospital, Institute of Medicine, Kathmandu 44600, Nepal \\ Int Arch Otorhinolaryngol 2022;26(4):e585-e591. \\ (e-mail: bijayaasim@gmail.com).
}

\begin{abstract}
Keywords

- abscess

- antibacterial drug resistance

- child

- neck

Introduction Neck space infection in the pediatric age group is common but can be life-threatening if not diagnosed properly. Since it is a polymicrobial disease, antibiotic usage should be guided by culture sensitivity pattern.

Objectives To assess the microbiology, antibiotic resistance pattern and the outcome of the medical and surgical management of deep neck space infection in children.

Methods This was a prospective study of children admitted for management of neck space infection from August 2017 to August 2018. The age, gender, organisms isolated, sensitivity and resistance to antibiotics, length of hospital stay, complications, and recurrence were noted. The descriptive data were analyzed.

Results Out of 108 cases, there were 51 males (47.2\%) and 57 females (52.8\%) ranging from 1 month to 15 years, with a mean age of $5.32+/-4.35$ years. The mean period of hospitalization was 6.98 days. Staphylococcus aureus was the most common organism isolated with less coagulase-negative staphylococci and streptococci. Clindamycin was the most sensitive drug (82.35\%) followed by vancomycin and cloxcillin, while amoxicillin/ampicillin, a commonly used drug, was the least sensitive (20.58\%). The abscess recurrence rate was $9.28 \%$. The outcomes of either medical treatment or a combined medical or surgical treatment in properly selected cases were comparable. Conclusion Clindamycin or cloxacillin can be used as a first-line option for neck infection in children. Ampicillin/amoxicillin alone has a small role in neck abscess because of high resistance to this type of antibiotic.
\end{abstract}

\section{Introduction}

Neck abscesses are very common in children and can be severe if deep neck spaces are involved. ${ }^{1}$ They may be potentially life-threatening with significant morbidity and mortality in children, especially in those with vague presentations and when physical examinations are difficult. ${ }^{2}$

Anatomically, the deep neck spaces are classified into three groups based on the relationship with the hyoid bone: spaces localized above the hyoid level (peritonsillar, submental, submandibular, parapharyngeal, buccal, parotid, masticatory/temporal, buccal, parotid); spaces that involve the entire circumference of the neck (retropharyngeal, danger space, prevertebral, and carotid); and the anterior or pretracheal visceral space, below the hyoid bone. ${ }^{3}$

Early diagnosis, appropriate antibiotic coverage, and drainage of collection play a key role in management. ${ }^{4}$ received

August 13, 2020

accepted after revision

October 20, 2021

published online

February 9, 2022
DOI https://doi.org/ 10.1055/s-0042-1744042. ISSN 1809-9777.

\footnotetext{
(c) 2022. Fundação Otorrinolaringologia. All rights reserved.

This is an open access article published by Thieme under the terms of the Creative Commons Attribution-NonDerivative-NonCommercial-License, permitting copying and reproduction so long as the original work is given appropriate credit. Contents may not be used for commercial purposes, or adapted, remixed, transformed or built upon. (https://creativecommons.org/ licenses/by-nc-nd/4.0/)

Thieme Revinter Publicações Ltda., Rua do Matoso 170, Rio de Janeiro, RJ, CEP 20270-135, Brazil
} 
Antibiotic resistance pattern in pediatric deep neck space infection current evidence recommends either medical treatment using antibiotics or surgical treatment guided by patient factors such as age, disease site. ${ }^{5}$ Because it is a polymicrobial disease, empirical antibiotics play a critical role in alleviating the clinical course of neck abscess while awaiting culture report. However, culture-guided antimicrobial therapy is the best clinical practice. ${ }^{6}$

The present study aimed to review the microbiology, antibiotic sensitivity, and resistance pattern of deep neck abscess. In addition, the outcome of management, including complication and recurrence rate, was also assessed.

\section{Materials and Methods}

\section{Study Population and Method}

A prospective study of pediatric patients admitted for management of neck space infection at the department of ENT and head and neck surgery was performed for 1 year from August 2017 to August 2018. The age, gender, symptoms and signs, organisms isolated with their sensitivity and resistance to antibiotics, the duration of abscess resolution, length of hospital stay, complications, and recurrence were noted. The outcomes, including complications, abscess resolution, and the length of hospitalization, were observed in the group managed exclusively with medical treatment as well as in the other group, managed with combined medical treatment and surgical intervention.

Patients presenting infection of both suprahyoid and infrahyoid spaces, such as submental, submandibular, peritonsillar, parotid, parapharyngeal, retropharyngeal spaces and anteroposterior triangle were included. Children with preexisting cyst with secondary infection, proven case of tubercular abscess, and abscesses secondary to otologic or orbital complications, were excluded. Any comorbidity predisposing to neck abscess was noted. All patients had empirical intravenous ampicillin and cloxacillin. Intravenous metronidazole was added in selected cases, depending on the clinical improvement. In addition to complete blood count, appropriate imaging of the affected site was done. The aspiration was done under ultrasonic guidance in the majority of the cases, except for peritonsillar and retropharyngeal abscess. Due to cost and time constraints, the abscess was drained without general anesthesia in the ward; however, adequate analgesia was provided. The abscess was drained under general anesthesia (GA) in cases of parapharyngeal abscess, necrotizing fasciitis, and cases with negative aspiration but needing urgent surgical intervention based on the clinical and radiological judgment in spite of negative aspirate. Cases of pus on aspiration indicating abscess and those requiring urgent attention underwent surgical drainage (incision and drainage [I\&D]). Pus either aspirated or drained was sent for culture and sensitivity. Patients with no pus on aspiration on USG guidance and minimal collection on ultrasound were medically managed. The patients were discharged with oral medications after improvement in the clinical symptoms, like fever, dysphagia, pain, and the laboratory parameters. Patients were discharged with oral antibiotics provided they showed improvement clinically and no further collection on either repeat ultrasound or computed tomography (CT) scan.

\section{Role of Imaging}

Ultrasonography was performed in all cases as the first-line investigation, except in cases of peritonsillar abscess and retropharyngeal space. A contrast-enhanced CT scan was performed in selected cases of parapharyngeal and retropharyngeal abscess as well as in cases with life-threatening complications and those in which ultrasonography (USG) did not yield enough information.

\section{Statistical Analysis}

Statistical analysis was performed using the IBM SPSS Statistics for Windows, Version 25.0 (IBM Corp., Armonk, NY, USA) software. The mean, frequencies, and range were calculated. The differences between groups were analyzed using the chi-squared test or the Fisher exact test for categorical data, and the $t$-test for continuous data, as appropriate, and significance was set at a $p$-value of 0.05 .

\section{Results}

\section{Population Characteristics}

There were 108 cases included in the study, out of which 51 were male (47.2\%) and 57 were female $(52.8 \%)$ patients. The age ranged from 5 months to 15 years, with the mean age being $5.39 \pm 4.35$ years. The majority of the children were younger than 5 years of age (60.16\%) (-Table 1). In our study, fever and painful neck swelling were the most common presentations.

\section{Self-medication Prior to Hospitalization}

Sixty-four (59.25\%) patients had taken medication prior to hospital admission (-Fig. 1). The most commonly prescribed drug was a combination of ampicillin and cloxacillin followed by azithromycin and a third-generation cephalosporin.

\section{Disease Pattern}

The majority of the cases were the submandibular and submental abscess secondary to the dental origin, sialadenitis, lymph node suppuration after upper respiratory tract infection (-Table 2).

Table 1 Age distribution of the children with neck space infection

\begin{tabular}{|l|l|l|}
\hline Age & Frequency & Percentage \\
\hline Up to 1 year & 24 & 22.22 \\
\hline $1-5$ years & 41 & 37.94 \\
\hline $5-10$ years & 26 & 24.07 \\
\hline $10-15$ years & 17 & 15.74 \\
\hline
\end{tabular}




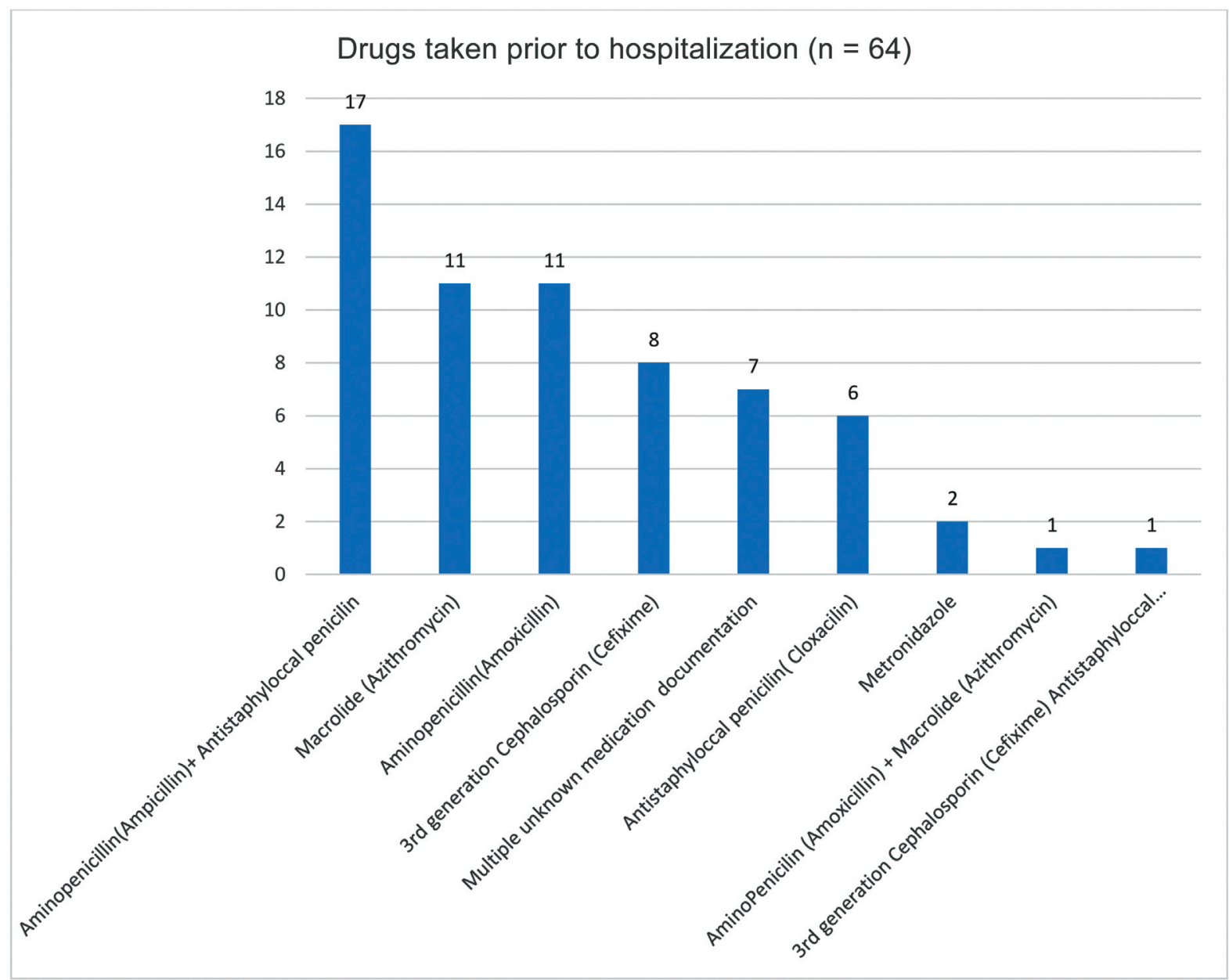

Fig. 1 Self-medication from the local medical shop before hospitalization.

Table 2 Site and pattern of the children with neck abscess

\begin{tabular}{|l|l|l|}
\hline Spaces localized above the hyoid level & Number & Percentage \\
\hline 1. Submandibular \& submental abscess & 55 & $50.9 \%$ \\
\hline 2. Parapharyngeal abscess & 23 & $21.29 \%$ \\
\hline 3. Peritonsillar abscess & 11 & $10.18 \%$ \\
\hline 4. Parotid abscess & 5 & $4.67 \%$ \\
\hline 5. Masticator/Temporal abscess & 3 & $2.78 \%$ \\
\hline 6. Ludwig's angina & 3 & $2.78 \%$ \\
\hline Spaces localized below the hyoid level & & \\
\hline 7. Anterior visceral & 1 & $0.92 \%$ \\
\hline Spaces localized in the entire circumference of the neck & & \\
\hline 8. Retropharyngeal abscess & 3 & $2.78 \%$ \\
\hline Miscellaneous & & \\
\hline 9. Necrotizing fasciitis of neck & 4 & $3.7 \%$ \\
\hline
\end{tabular}

\section{Bacterial Growth in the Pus Cultures}

Positive Bacterial Growth in the Pus Culture Out of 108 cases, pus culture was sent in 85 cases, 41 of which showed positive culture (48.3\%). Staphylococcus au- reus was the most common organism isolated, which was followed by coagulase-negative staphylococci. There were three cases of methicillin-resistant staphylococci isolated (-Fig. 2). 


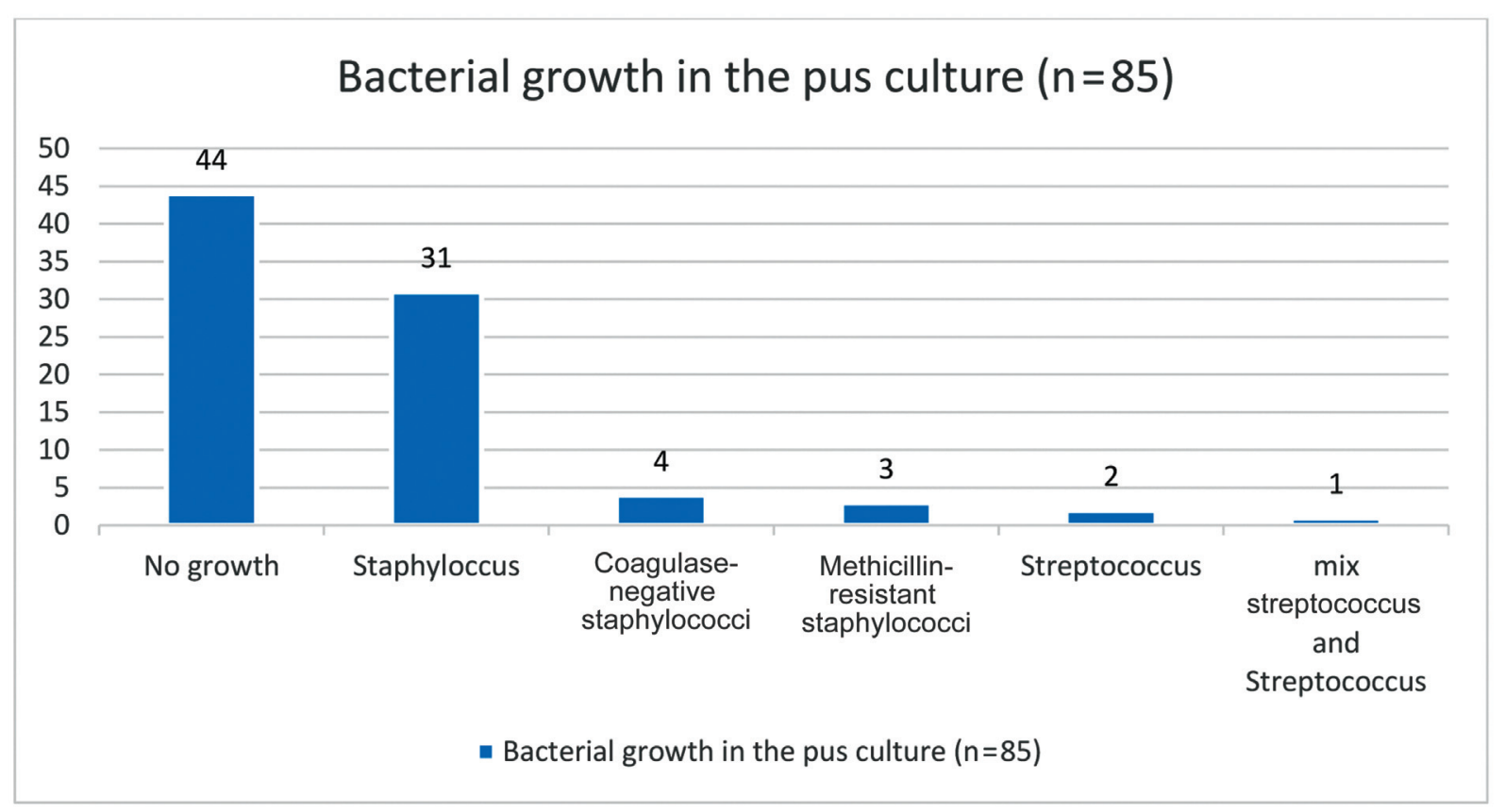

Fig. 2 Bacterial growth in the pus culture in children with neck abscess.

3.4.2 No bacterial growth in the pus culture: out of 85 cases, 44 cases $(51.76 \%)$ did not show any growth in the culture.

\section{Drug Sensitivity and Resistance Pattern with Various Drugs among Positive Growth with Staphylococcus Aureus}

Only the sensitivity pattern of the most commonly used drugs was taken. In S. aureus, sensitivity was the highest to clindamycin (82.35\%) followed by vancomycin $(73.53 \%)$ and cloxacillin (73.53\%). The most commonly used drug, amoxicillin/ampicillin, had the lowest sensitivity (20.58) (-Table 3). Coagulase-negative staphylococci also had a similar sensitivity pattern ( - Table 4$)$.

\section{Abscess Resolution}

Overall, $90.74 \%$ of cases improved after the initial treatment whether medically or combined with surgical drainage.

Table 3 Antibiotic sensitivity pattern for Staphylococcus aureus in the pus culture

\begin{tabular}{|c|c|c|c|c|}
\hline \multicolumn{5}{|c|}{ Sensitivity pattern of Staphylococcus aureus $(\mathrm{n}=34)$} \\
\hline \multirow[t]{2}{*}{ Drug } & \multicolumn{4}{|c|}{ Sensitivity pattern } \\
\hline & \multicolumn{2}{|c|}{ Sensitivity } & \multicolumn{2}{|c|}{ Resistance } \\
\hline Clindamycin & 28 & $(82.35 \%)$ & 6 & $(17.64 \%)$ \\
\hline Vancomycin & 25 & $(73.53 \%)$ & 9 & $(26.47 \%)$ \\
\hline Cloxacillin & 24 & $(70.59 \%)$ & 10 & $(29.41 \%)$ \\
\hline Gentamycin & 23 & (67.64\%) & 11 & $(32.36 \%)$ \\
\hline Amikacin & 23 & $(67.64 \%)$ & 11 & $(32.36 \%)$ \\
\hline Chloramphenicol & 15 & $(44.11 \%)$ & 19 & $(55.89 \%)$ \\
\hline Erythromycin & 10 & $(29.41 \%)$ & 24 & $(70.58 \%)$ \\
\hline Ciprofloxacin & 9 & $(26.47 \%)$ & 25 & $(73.53 \%)$ \\
\hline Doxycycline & 9 & (26.47\%) & 25 & (73.53\%) \\
\hline Levofloxacin & 7 & (20.58\%) & 27 & (79.42\%) \\
\hline Ampicillin/Amoxicillin & 7 & (20.58\%) & 27 & $(79.42 \%)$ \\
\hline
\end{tabular}


Table 4 Antibiotic sensitivity pattern for coagulase-negative staphylococci in the pus culture

\begin{tabular}{|l|l|l|l|l|}
\hline \multirow{2}{*}{ Sensitivity pattern of Coagulase-negative staphylococci $(\boldsymbol{n}=4)$} \\
\cline { 2 - 5 } & Sensitivity pattern & \multicolumn{4}{l|}{} \\
\cline { 2 - 5 } & Sensitivity & $(100 \%)$ & \multicolumn{2}{l|}{ Resistance } \\
\hline Clindamycin & 4 & $(100 \%)$ & 0 & \\
\hline Vancomycin & 4 & $(75 \%)$ & 0 & $(25 \%)$ \\
\hline Cloxacillin & 3 & $(50 \%)$ & 1 & $(50 \%)$ \\
\hline Amikacin & 2 & $(50 \%)$ & 2 & $(50 \%)$ \\
\hline Gentamycin & 2 & $(50 \%)$ & 2 & $(50 \%)$ \\
\hline Chloramphenicol & 2 & $(50 \%)$ & 2 & $(50 \%)$ \\
\hline Ciprofloxacin & 2 & $(50 \%)$ & 2 & $(50 \%)$ \\
\hline Doxycycline & 2 & $(50 \%)$ & 2 & $(50 \%)$ \\
\hline Levofloxacin & 2 & $(50 \%)$ & 2 & $(75 \%)$ \\
\hline Erythromycin & 2 & & 3 & $(100 \%)$ \\
\hline Ampicillin/Amoxicillin & 1 & 4 & 2 & \\
\hline
\end{tabular}

\section{Abscess Recurrence}

There was recurrence in 10 cases, out of which 2 had multiple episodes of recurrence ( - Table 5 and $\mathbf{6}$ ).

\section{Complications}

There was no complication including mortality noted in the study.

\section{Length of Hospitalization}

The mean hospital stay was 6.94 days. The mean duration of stay in the group with medical management was 10.62 days, compared with 6.11 days, with a $p$-value of 0.07 (-Table 7).

\section{Discussion}

Infections and abscesses around the neck are common in young children mostly due to lymph node suppuration secondary to upper respiratory tract infection (URTI) or pharyngeal infection. The other sources of infection in the neck leading to abscess formation are of dental origin, infections of salivary glands, and cystic lesions of the neck. ${ }^{7}$

Fever is an invariable symptom in most neck abscesses. Other symptoms, like odynophagia, drooling, and painful neck swelling, may not be very specific for parapharyngeal, retropharyngeal, or peritonsillar abscesses; thus, this may lead to difficulty in diagnosis in children. In our study, fever and painful neck swelling were the most common presenta-

Table 5 Recurrence rate among the children

\begin{tabular}{|l|l|l|}
\hline & Frequency & Percentage \\
\hline None & 98 & 90.74 \\
\hline Single recurrence & 8 & 7.41 \\
\hline Multiple recurrence & 2 & 1.85 \\
\hline Total & 108 & 100.0 \\
\hline
\end{tabular}

tions for all pediatric patients. The most common age range was 1 to 5 years, with the mean age being 5.32 years, which tallied with other studies. ${ }^{8,9}$ The younger spectrum of patients being more affected could be related to an immature immune system. ${ }^{9}$ There was no observed difference in gender distribution.

In the present study, 44 cases (51.76\%) did not show any growth in culture. Such a large number of negative culture growth could be due to self-medication with antibiotics prior to hospital admission. Sixty-four (59.25\%) patients had taken medication prior to hospital admission, 37 patients had been prescribed over-the-counter penicillin group of drug, either alone as a combination, and referred to a specialist after the non-resolution of the symptom. Azithromycin was prescribed in $12 \%(13 / 108)$ of cases, with a single dose daily for 5 days. According to the systematic review done by Nepal et al., ${ }^{10}$ the prevalence of self-medication with antibiotics (SMA) in Southeast Asia ranged from 7.3 to $85.59 \%$, with an overall prevalence of $42.64 \%$. The other possibility could be an atypical mycobacterial infection, which is not included in the routine culture sensitivity tests.

Among the positive culture growth, the most common organism isolated was staphylococcus, which was similar to the findings of various published studies. ${ }^{4,7}$ The most sensitive antibiotic was clindamycin in 28 cases (82.25\%), followed by vancomycin and cloxacillin. This is similar to the findings in the published literature. ${ }^{7}$ The reason for this may be clindamycin is active against staphylococci, penicillinresistant strains of Streptococcus pneumoniae, Streptococcus pyogenes, and viridans streptococci as well as most anaerobes. Clindamycin also reduces some virulence factors of microbes, such as toxin production by $S$. aureus, Clostridium, and capsule formation by S. pyogenes, and S. pneumoniae, and it enhances phagocytosis of susceptible organisms. ${ }^{11}$

Staphylococcus aureus with resistance to multiple antibiotics, like methicillin-resistant Staphylococcus aureus (MRSA), is highest in Asia. ${ }^{12}$ Similarly, a higher resistance 
Table 6 Details of the children with recurrence

\begin{tabular}{|l|l|l|l|l|l|l|l|}
\hline Recurrence & $\begin{array}{l}\text { Age in } \\
\text { years }\end{array}$ & Episode & $\begin{array}{l}\text { Previous } \\
\text { management }\end{array}$ & Space involved & $\begin{array}{l}\text { Collection } \\
\text { size } \\
\text { noted in } \\
\text { previous } \\
\text { episode (in ml) }\end{array}$ & $\begin{array}{l}\text { Possible reason } \\
\text { for recurrence }\end{array}$ & $\begin{array}{l}\text { Days of } \\
\text { previous } \\
\text { stay }\end{array}$ \\
\hline Recurrence 1 & 5 & Multiple & Surgical & $\begin{array}{l}\text { Parotid / } \\
\text { Parapharyngeal }\end{array}$ & 15 & Inadequate drainage & 10 \\
\hline Recurrence 2 & 5 & Single & Surgical & Submandibular & 5 & $\begin{array}{l}\text { Inadequate } \\
\text { drainage short } \\
\text { duration of treatment }\end{array}$ & 5 \\
\hline Recurrence 3 & 3 & Single & Surgical & Parapharyngeal & 20 & - & 8 \\
\hline Recurrence 4 & 5 & Single & Surgical & Parotid & 5 & - & 15 \\
\hline Recurrence 5 & 15 & Single & Surgical & Parapharyngeal & 18 & - & 12 \\
\hline Recurrence 6 & 6 & Single & Surgical & Parotid & 30 & $\begin{array}{l}\text { Inadequate } \\
\text { drainage }\end{array}$ & 8 \\
\hline Recurrence 7 & 10 & Single & Surgical & Submandibular & 15 & - & 9 \\
\hline Recurrence 8 & 7 & Single & Surgical & Submandibular & 5 & - & 8 \\
\hline Recurrence 9 & 2 & Multiple & Surgical & $\begin{array}{l}\text { Necrotizing } \\
\text { fasciitis of neck }\end{array}$ & 8 & Immunocompromised & 108 \\
\hline Recurrence 10 & 1 & Single & Surgical & Submandibular & 8 & - & 10 \\
\hline
\end{tabular}

Table 7 Difference in the medical management group alone versus medical and surgical management group

\begin{tabular}{|l|l|l|l|l|l|}
\hline \multicolumn{2}{|l|}{} & Overall & Medical and surgical management & Medical management only & $p$-value \\
\hline \multirow{2}{*}{ Gender } & Male (51) & & 38 & 13 & 0.133 \\
\cline { 2 - 5 } & Female(57) & & 49 & 8 & \\
\hline Age & 5.39 & 5.058 & 6.774 & 0.105 \\
\hline $\begin{array}{l}\text { Total count prior to } \\
\text { admission }\end{array}$ & 15389 & 16040 & 12693 & 0.009 \\
\hline Days of stay & 6.98 & 6.11 & 10.62 & 0.07 \\
\hline Recurrence rate & & $(8 / 78) 10.2 \%$ & $(2 / 20) 10 \%$ & 1 \\
\hline
\end{tabular}

pattern is seen in low developing countries, such as those in sub-Saharan Africa. ${ }^{13}$ This is a matter of concern, especially in the context of pediatric deep neck space infection, in which life-threatening complications can occur despite early treatment with commonly used drugs, such as those in penicillin group (amoxicillin/ampicillin).

Ampicillin and amoxicillin are not penicillinase-resistant and, therefore, had a low sensitivity of $17.03 \%$ and a high resistance pattern. Considering the safety profile, among the oral penicillin group of drugs, cloxacillin had the highest sensitivity.

The recurrence rate was $9.26 \%$ (10/108), of which 8 cases had a single recurrence and 2 cases had more than 1 . There were three cases with a single recurrence due to inadequate drainage during the first treatment. All cases with multiple recurrences had multiple neck space involvement. One case with necrotizing fasciitis secondary to immune suppression had a prolonged stay and repeated recurrence with a chest infection. The recurrence rate was high in young children (mostly below 7 years of age). The small size of young babies with difficult anatomic location was likely the cause for the difficult drainage and often inadequate drainage which might be the possible reason for the high recurrence rate in our study. The repeat CT scan was not feasible in every case because of the financial constraints, so, clinical judgment and ultrasonography were used as discharge criteria as a parameter for subsidence of the abscess. Parapharyngeal and parotid abscess with deep collection which are often missed, could be the possible reason for high recurrence. Recurrence was common in both the small size and large size collections, and inadequate drainage was the main reason for recurrence.

The mean duration of stay was longer in the group with medical management as compared with those with medical treatment and surgical drainage ( - Table 7 ). Higher leukocyte count was found in surgically managed cases when compared with those who needed only medical management. Higher leukocyte count might predict the long duration of infection with pus formation and hence the need for 
incision and drainage. Slightly raised leukocyte count indicates an early inflammation period (cellulitis stage) with no abscess formation.

Potential life-threatening complications can arise despite using multiple medications. The complications rate in pediatrics neck space abscesses is variable with the complication rate in literature ranging from 9 to $12 \%{ }^{2,14,15}$ However, there was no complication noted in our study.

Patigaroo et al. and Ossowski et al. emphasize surgical drainage to minimize the time in the hospital and accelerates resolution. ${ }^{2,16}$ However, the published study in parapharyngeal and retropharyngeal space infection show the comparable outcome of conservative management to surgical intervention in deep neck space. ${ }^{17,18}$

The treatment of neck space abscess consists of medical treatment, surgical intervention, and management of complications. Due to the lack of universal consensus regarding the approach to indications of surgical intervention, empirical choice, and duration of antibiotic, the treatment should be individualized depending on the clinical response. ${ }^{7}$

The limitation of this study is that the culture and sensitivity pattern was not tested with anaerobic organisms in all cases because of the problem in transport and culture media. Similarly, the sensitivity testing of a commonly used drug, amoxicillin combined with clavulanic acid, is lacking in this study as this is not always included in the routine test. The small sample size is another potential limitation of the study.

\section{Conclusion}

The majority of neck abscess was due to staphylococcus. The empirical drug of choice for deep neck space infection in pediatric patients is clindamycin or cloxacillin, which should be followed by culture-guided appropriate antibiotics. Antistaphylococcal drug (cloxacillin) alone should be used instead of a combination of ampicillin and cloxacillin as the resistance to ampicillin is high. In an early presentation with only slightly raised leukocyte count, the conservative management with appropriate intravenous antibiotic alone is a good option.

\section{Ethical Consideration}

Ethical clearance was obtained from the institutional review board with approval number $10(6-11) E^{2} 77 / 78$.

\section{Conflict of Interests}

The authors have no conflict of interests to declare.

\section{References}

1 Elden LM, Grundfast KM, Vezina G. Accuracy and usefulness of radiographic assessment of cervical neck infections in children. J Otolaryngol 2001;30(02):82-89

2 Patigaroo SA, Patigaroo FA, Mehfooz N, Khan NA, Kirmani MH. Shakeel. Paediatric Deep Neck Space Abscesses: A Prospective Observational Study. Emerg Med 2012;2(117):2-7. Doi: 10.4172/ 2165-7548.1000117

3 Vieira F, Allen SM, Stocks RM, Thompson JW. Deep neck infection. Otolaryngol Clin North Am 2008;41(03):459-483, vii

4 Rustom IK, Sandoe JA, Makura ZG. Paediatric neck abscesses: microbiology and management. J Laryngol Otol 2008;122(05): 480-484

5 Lawrence R, Bateman N. Controversies in the management of deep neck space infection in children: an evidence-based review. Clin Otolaryngol 2017;42(01):156-163

6 Lee YQ Kanagalingam J. Bacteriology of deep neck abscesses: a retrospective review of 96 consecutive cases. Singapore Med J 2011;52(05):351-355

7 Metin Ö, Öz FN, Tanır G, et al. Deep neck infections in children: experience in a tertiary care center in Turkey. Turk J Pediatr 2014; 56(03):272-279

8 Nagy M, Pizzuto M, Backstrom J, Brodsky L. Deep neck infections in children: a new approach to diagnosis and treatment. Laryngoscope 1997;107(12 Pt 1):1627-1634

9 Coticchia JM, Getnick GS, Yun RD, Arnold JE. Age-, site-, and timespecific differences in pediatric deep neck abscesses. Arch Otolaryngol Head Neck Surg 2004;130(02):201-207

10 Nepal G, Bhatta S. Self-medication with antibiotics in WHO Southeast Asian Region: a systematic review. Cureus 2018;10(04):e2428

11 Brook I. Microbiology and principles of antimicrobial therapy for head and neck infections. Infect Dis Clin North Am 2007;21(02): 355-391, vi

12 Chen CJ, Huang YC. New epidemiology of Staphylococcus aureus infection in Asia. Clin Microbiol Infect 2014;20(07):605-623

13 Bebell LM, Muiru AN. Antibiotic use and emerging resistance: how can resource-limited countries turn the tide? Glob Heart 2014;9(03):347-358

14 Baldassari CM, Howell R, Amorn M, Budacki R, Choi S, Pena M. Complications in pediatric deep neck space abscesses. Otolaryngol Head Neck Surg 2011;144(04):592-595

15 Elsherif AM, Park AH, Alder SC, Smith ME, Muntz HR, Grimmer F. Indicators of a more complicated clinical course for pediatric patients with retropharyngeal abscess. Int J Pediatr Otorhinolaryngol 2010;74(02):198-201

16 Ossowski K, Chun RH, Suskind D, Baroody FM. Increased isolation of methicillin-resistant Staphylococcus aureus in pediatric head and neck abscesses. Arch Otolaryngol Head Neck Surg 2006;132 (11):1176-1181

$17 \mathrm{Oh} \mathrm{JH}$, Kim Y, Kim CH. Parapharyngeal abscess: comprehensive management protocol. ORL J Otorhinolaryngol Relat Spec 2007; 69(01):37-42

18 Thompson JW, Cohen SR, Reddix P. Retropharyngeal abscess in children: a retrospective and historical analysis. Laryngoscope 1988;98(6 Pt 1):589-592 